UDC 343.152 .9

LBC 67.410.206

\title{
THE DEFENDANT'S CONSENT WITH THE ACCUSATION AS A CONDITION OF THE LEGITIMACY OF PRE-RIAL AGREEMENT ON COOPERATION
}

\author{
Olga N. Tisen \\ Prosecutors Office of the Orenburg Region, Orenburg, Russian Federation
}

Introduction. Prior to the introduction of the legislator's amendments to Chapter 40.1 of the criminal procedure code of the Russian Federation in July 2016, the question whether the agreement with the prosecution is a prerequisite for the legality of pre-trial agreement on cooperation has caused heated debates among scientists and practitioners. However, after the inclusion of a provision on possible change of the pre-trial agreement in Chapter 40.1 of the code of criminal procedure, this issue has acquired even greater urgency. Results. Based on the analysis of current legislation and judicial practice the author argues the position that the consent of the accused with the accusation is a prerequisite for the legitimacy of pre-trial agreement on cooperation. The notion of "guilty plea" and "consent with the prosecution" are not equivalent from the point of view of their criminal procedural sense. Conclusions. The change of charges in the direction of deterioration prosecuted may entail a significant transformation of the conditions of cooperation with law enforcement. In this regard, the article substantiates a point of view about the need of renewal of pre-trial agreement on cooperation in case of being charged a more serious crime and proposes a procedure for implementing this procedure in practice.

Key words: pre-trial agreement on cooperation, admission of guilt, the defendants' consent with accusation, accusation change, deterioration of the situation of the accused.

УДК 343.152 .9

ББК 67.410 .206

\section{СОГЛАСИЕ ОБВИНЯЕМОГО С ПРЕДЬЯВЛЕННЫМ ОБВИНЕНИЕМ КАК УСЛОВИЕ ЛЕГИТИМНОСТИ ДОСУДЕБНОГО СОГЛАШЕНИЯ О СОТРУДНИЧЕСТВЕ СО СЛЕДСТВИЕМ}

\author{
Ольга Николаевна Тисен \\ Прокуратура Оренбургской области, г. Оренбург, Российская Федерация
}

\begin{abstract}
Введение: до внесения в июле 2016 г. законодателем изменений в главу 40.1 УПК РФ вопрос о том, является ли согласие с предъявленным обвинением обязательным условием законности досудебного соглашения о сотрудничестве, вызывал острые дискуссии среди ученых и практикующих юристов. Однако после включения в эту главу нормы о возможности изменения досудебного соглашения этот вопрос приобрел еще большую актуальность. Результаты: на основании анализа действующего законодательства и судебной практики аргументирована позиция о том, что согласие обвиняемого с предъявленным обвинением является 6 обязательным условием легитимности досудебного соглашения о сотрудничестве. При этом понятия «признание вины» и «согласие с предъявленным обвинением» не являются равнозначными с точки зрения их уголовно-процессуального смысла. Выводы: изменение обвинения в сторону ухудшения положения привлеченного к уголовной ответственности может повлечь за собой существенную трансформацию условий со сотрудничества с правоохранительными органами. В этой связи в статье обосновывается точка зрения о необходимости перезаключения досудебного соглашения о сотрудничестве в случае предъявления обвине() ния в более тяжком преступлении и предлагается порядок реализации этой процедуры на практике.
\end{abstract}


Ключевые слова: досудебное соглашение о сотрудничестве, признание вины, согласие с предъявленным обвинением, изменение обвинения, ухудшение положения обвиняемого.

\section{Введение}

До июля 2016 г. Уголовно-процессуальный кодекс РФ прямо не предусматривал необходимости получения от обвиняемого согласия с предъявленным обвинением в качестве условия применения института досудебного соглашения о сотрудничестве [14]. Однако п. 15 Постановления Пленума Верховного суда «О практике применения судами особого порядка судебного разбирательства уголовных дел при заключении досудебного соглашения о сотрудничестве» от 28 июня 2012 г. № 16 [8] указывал, что рассмотрение уголовного дела в порядке ст. 317.7 УПК РФ возможно лишь при согласии обвиняемого с предъявленным обвинением. Если подсудимый не в полной мере признает инкриминируемое, суд должен принять решение о прекращении особого производства и назначить судебное разбирательство в общем порядке.

\section{Значение согласия \\ с предъявленным обвинением для применения главы 40.1 УПК РФ}

Федеральным законом «О внесении изменений в Уголовно-процессуальный кодекс Российской Федерации по вопросу совершенствования порядка судопроизводства при заключении досудебного соглашения о сотрудничестве» от 3 июля 2016 г. № 322-Ф3 ч. 1 ст. 317.5 УПК РФ была дополнена требованием о согласии обвиняемого с предъявленным обвинением в качестве одного из условий вынесения прокурором представления об особом порядке проведения судебного заседания и вынесения судебного решения в отношении лица, с которым заключено досудебное соглашение о сотрудничестве [14].

Применение ст. 317.7 УПК РФ при рассмотрении уголовного дела в отношении лица, оспаривающего предъявленное обвинение, теряет всякий смысл, поскольку при отсутствии раскаяния опасность оговора других лиц многократно возрастает.
Первоначально проект закона, предусматривающий введение в российский уголовный процесс института досудебного соглашения о сотрудничестве, содержал требование о необходимости признания его субъектом своей вины. Однако на одном из заседаний круглого стола в Государственной Думе Федерального Собрания Российской Федерации, посвященном обсуждению законопроекта, председатель Верховного суда РФ А.Б. Лебедев указал, что «положения этой главы применяются ....независимо от того, согласился ли обвиняемый с выдвинутыми против него обвинениями... В то же время положения главы 40.1 УПК РФ об определении меры наказания необходимо применять только в отношении тех преступлений, вину в совершении которых обвиняемый полностью признал» [6, с. 8$]$.

До принятия Пленумом Верховного суда РФ Постановления от 28 июня 2012 г. № 16 многие авторы полагали, что досудебное соглашение будет легитимно и в случае отрицания обвиняемым своей причастности к инкриминируемому деянию [9, с. 134]. Такую точку зрения высказывали А.В. Смирнов [10, с. 6], М.Е. Кубрикова [3]. Исследуемому вопросу посвящали свои научные работы и другие ученые $[1 ; 2 ; 4 ; 7]$.

\section{Разграничение значения понятий «признание вины» и «согласие с предьявленным обвинением»}

Отметим, что российский институт досудебного соглашения о сотрудничестве существенно отличается от американских сделок о признании вины. Прежде всего американская процедура, в отличие от отечественной, предполагает необходимость признания обвиняемым своей вины, тогда как обязательным условием российского особого порядка судебного разбирательства является согласие с предъявленным обвинением. Принципиальная разница приведенных понятий состоит в том, что признание вины может и не предполагать согласие с позицией прокурора о квалификации действий обвиняемого. В свою оче- 
редь согласие с предъявленным обвинением означает отсутствие разногласий между мнениями прокурора и обвиняемого относительно фабулы и квалификации действий последнего. Таким образом, институт досудебного соглашения о сотрудничестве и особый порядок судебного разбирательства могут иметь место лишь в том случае, если обвиняемый фактически заявляет о правильности изложения в обвинительном заключении признаков совершенного им преступления и конкретных обстоятельств содеянного, а также юридической оценки его действий, изложенной в конкретной статье Уголовного закона.

В следственной практике встречаются случаи заключения досудебного соглашения с обвиняемыми, не признающими свою вину.

Так, 4 марта 2013 г. заместителем прокурора г. Оренбурга заключено досудебное соглашение с Г., обвиняемым по ч. 4 ст. 158 УК РФ. Вопреки требованиям главы 40.1 УПК РФ и разъяснениям, содержащимся в Постановлении Пленума Верховного суда РФ от 28 июня 2012 г. № 16, субъект досудебного соглашения не признавал свою вину. На основании изложенного прокурор г. Оренбурга вынес постановление о расторжении досудебного соглашения о сотрудничестве с Г. [13].

\section{Внесение изменений}

\section{в досудебное соглашение о сотрудничестве}

В ходе расследования почти каждого уголовного дела о преступлениях, совершенных в соучастии, возникает необходимость перепредъявления обвинения. Это может быть связано с выявлением новых эпизодов преступной деятельности, установлением ранее неизвестных соучастников либо уточнением квалификации совершенных деяний. Поскольку, как правило, досудебное соглашение о сотрудничестве заключается на ранних этапах расследования, в его установочной части отражается первоначальное обвинение, теряющее свою актуальность к моменту составления обвинительного заключения. Однако после изменения обвинения субъект досудебного соглашения может отказаться от исполнения условий ранее заключенного досудебного соглашения, что повлечет за собой его расторжение.
Полагаем, что наличие противоречий между обвинением, изложенным в тексте досудебного соглашения о сотрудничестве, и обвинительным заключением ставит под сомнение его легитимность, поскольку изменение обвинения в сторону ухудшения положения привлеченного к уголовной ответственности может повлечь за собой существенную трансформацию условий сотрудничества с правоохранительными органами. Кроме того, согласие с предъявленным на первоначальном этапе расследования «дежурным» обвинением не означает, что субъект досудебного соглашения в последующем признает изложенное в новом постановлении о привлечении в качестве обвиняемого.

Изменение в одностороннем порядке условий досудебного соглашения в сторону ухудшения положения обвиняемого противоречит его существу, поскольку сотрудничество с правоохранительными органами является правом, а не обязанностью привлеченного к уголовной ответственности.

Полагаем, что предъявление сотрудничающему с правоохранительными органами лицу нового обвинения, ухудшающего его положение, должно влечь за собой перезаключение досудебного соглашения.

По нашему мнению, досудебное соглашение будет отвечать отраженным в главе 40.1 УПК РФ требованиям лишь в случае соответствия описания отраженного в его тексте обвинения зафиксированному в постановлении о привлечении в качестве обвиняемого.

Отраженная нами позиция о необходимости перезаключения досудебного соглашения о сотрудничестве в случае предъявления его субъекту обвинения, ухудшающего его положение, встречается в судебных решениях.

Так, в 2015 г. Абдулинский районный суд Оренбургской области возвратил прокурору в порядке ст. 237 УПК РФ поступившее с предусмотренным ст. 317.5 УПК РФ представлением прокурора уголовное дело в отношении обвиняемой в сбыте наркотических средств в составе организованной преступной группы. В постановлении суд указал, что предъявление после заключения досудебного соглашения о сотрудничестве обвинения в более тяжком преступлении ухудшает положение обвиняемой, а потому законность пред- 
варительного расследования в порядке главы 40.1 УПК РФ вызывает сомнения. При этом в ходе предварительного слушания, назначенного судом по собственной инициативе, обвиняемая полностью соглашалась с предъявленным обвинением и настаивала на рассмотрении уголовного дела в порядке главы 40.1 УПК РФ [12].

В случае несогласия сотрудничающего со следствием лица с новым обвинением ранее заключенное досудебное соглашение о сотрудничестве подлежит расторжению. При этом его содействие в раскрытии и расследовании преступлений должно быть учтено в качестве обстоятельства, смягчающего наказание.

Федеральным законом от 3 июля 2016 г. № 322-ФЗ ст. 37 УПК РФ была дополнена нормой, предоставляющей прокурору право вносить изменения в досудебное соглашение о сотрудничестве посредством вынесения постановления [14]. Уголовно-процессуальное законодательство и до этого не содержало прямого запрета на внесение изменений в текст ранее заключенного досудебного соглашения. Однако процедура его корректировки не регламентирована до сих пор.

В новой редакции ч. 5 ст. 317.4 УПК РФ указывает на возможность вынесения прокурором постановления об изменении либо прекращении действия досудебного соглашения при наличии следующих обстоятельств:

1) сообщение подозреваемым или обвиняемым лишь сведений о собственном участии в совершенном деянии или сведений, уже известных органам предварительного расследования;

2) отказ от дачи показаний, изобличающих других соучастников преступления;

3) выявление данных, свидетельствующих о несоблюдении подозреваемым или обвиняемым условий и невыполнении обязательств, предусмотренных досудебным соглашением о сотрудничестве.

Часть 5 ст. 317.4 УПК РФ не разграничивает оснований для отмены и изменения ранее заключенного досудебного соглашения о сотрудничестве. Полагаем, что с учетом условий легитимности досудебного соглашения приведенные в указанной норме основания влекут за собой прекращение действия досудеб- ного соглашения, поскольку каждое из них препятствует применению порядка, регламентированного главой 40.1 УПК РФ.

Полагаем, что порядок перезаключения досудебного соглашения о сотрудничестве должен быть регламентирован в УПК РФ следующим образом.

После предъявления обвинения при последующем допросе субъекта досудебного соглашения необходимо уделить особое внимание его позиции относительно дальнейшего сотрудничества со следствием. В случае согласия обвиняемого с предъявленным обвинением и намерения продолжить исполнение взятых на себя в рамках ранее заключенного досудебного соглашения обязательств следователь с согласия руководителя следственного органа должен вынести мотивированное постановление о возбуждении перед прокурором ходатайства о прекращении досудебного соглашения в связи с перепредъявлением обвинения и необходимостью заключения нового.

В течение трех суток с момента поступления от следователя указанного процессуального документа прокурор должен вынести постановление об удовлетворении либо отказе в удовлетворении ходатайства следователя и прекращении действия ранее заключенного досудебного соглашения. После этого прокурор с участием следователя, обвиняемого и его защитника заключает новое досудебное соглашение о сотрудничестве, в котором, помимо прочего, должна быть отражена фабула обвинения, соответствующая изложенной в постановлении о привлечении в качестве обвиняемого.

Первоначальное досудебное соглашение о сотрудничестве должно храниться в материалах уголовного дела и подлежит исследованию в судебном заседании в целях всестороннего исполнения требований, предусмотренных ст. 317.7 УПК РФ.

\section{Выводы}

Согласие обвиняемого с предъявленным обвинением является важнейшим условием легитимности досудебного соглашения о сотрудничестве, нарушение которого влечет его ничтожность. При поступлении в суд уголов- 
ного дела с досудебным соглашением с обвиняемым, не в полной мере согласившимся с предъявленным обвинением, по смыслу главы 40.1 УПК РФ суд должен вернуть его прокурору в порядке ст. 237 УПК РФ.

Полагаем, что соответствие изложенного в досудебном соглашении о сотрудничестве обвинения отраженному в постановлении о привлечении в качестве обвиняемого исключит возможные сомнения суда относительно соблюдения требований главы 40.1 УПК РФ при расследовании уголовного дела и будет соответствовать позиции Верховного суда Российской Федерации, изложенной в Постановлении Пленума от 28 июня 2012 г. № 16.

\section{СПИСОК ЛИТЕРАТУРЫ}

1. Белкин, А. Р. Досудебное соглашение о сотрудничестве нуждается в коррективах / А. Р. Белкин // Досудебное соглашение о сотрудничестве (правовые и криминалистические проблемы). - Воронеж : Изд-во Воронеж. гос. ун-та, 2010. - С. 73-84.

2. Костенко, Н. С. Досудебное соглашение о сотрудничестве в уголовном процессе: правовые и организационные вопросы заключения и реализации : дис. ... канд. юрид. наук / Костенко Наталья Сергеевна. - Волгоград, 2013.-238 с.

3. Кубрикова, М. Е. Актуальные вопросы института досудебного соглашения о сотрудничестве : автореф. дис. ... канд. юрид. наук / Кубрикова Мария Евгеньевна. - Челябинск, 2013. - 25 с.

4. Перекрестов, В. Н. Признание вины в отечественном уголовном судопроизводстве Российской Федерации : автореф. дис. ... канд. юрид. наук / Перекрестов Вадим Николаевич. - Краснодар, 2012. $-29 \mathrm{c}$.

5. Перекрестов, В. Н. Совершенствование системы гарантий добровольности признания вины как направление модернизации уголовно-процессуального законодательства / В. Н. Перекрестов // Вестник Волгоградского государственного университета. Серия 5, Юриспруденция. - 2013. - № 2 (19). - C. 160-164.

6. Перспективы введения в Российской Федерации института «сделки с правосудием» : материалы парламент. круглого стола в Гос. Думе Федер. Собр. Рос. Федерации (8 февр. 2007 г.) / под общ. ред. С. А. Глотова. - М. : Издание Гос. Думы, 2007. $-40 \mathrm{c}$.

7. Погодин, С. Б. Некоторые актуальные проблемы применения особого порядка судебного разбирательства в состязательном уголовном процес- се / С. Б. Погодин // Российская юстиция. - 2009. № 9. - C. 61-65.

8. Постановление Пленума ВС РФ «О практике применения судами особого порядка судебного разбирательства уголовных дел при заключении досудебного соглашения о сотрудничестве» от 28 июня 2012 г. № 16 // Бюллетень Верховного Суда Российской Федерации. - 2012. - № 9. - С. 19-22.

9. Саркисян, Т. Б. Согласительные процедуры в уголовном судопроизводстве и их применение в стадии предварительного расследования : дис. ... канд. юрид. наук / Саркисян Тигран Борисович. Краснодар, 2012. - 201 c.

10. Смирнов, А. В. Особый порядок принятия судебного решения при заключении досудебного соглашения о сотрудничестве / А. В. Смирнов // Уголовный процесс. - 2009. - № 10. - С. 5-14.

11. Справка о результатах обобщения практики применения судами Саратовской области в 2010 году и первом полугодии 2011 года норм об особом порядке принятия судебного решения при заключении досудебного соглашения о сотрудничестве от 21.11.2011 // Саратовский областной суд : офиц. сайт. - Электрон. текстовые дан. - Режим доступа: http://oblsud.sar.sudrf.ru. - Загл. с экрана.

12. Уголовное дело № 13/122-2014 в отношении В., обвиняемой в совершении преступлений, предусмотренных ч. 3 ст. 30 , п. «а» ч. 4 ст. 228.1 , ч. 1 ст. 30 , п. «а, г» ч. 4 ст. 228.1 , ч. 1 ст. 30 , п. «а» ч. 4 ст. 228.1 , ч. 1 ст. 30 , п. «а» ч. 4 ст. 228.1 , ч. 4 ст. 150 УК РФ // Действующий архив Абдулинского районного суда Оренбургской области за 2015 год.

13. Уголовное дело № 60/141-2014 в отношении Г. // Действующий архив Дзержинского районного суда г. Оренбурга.

14. Федеральный закон «О внесении изменений в Уголовно-процессуальный кодекс Российской Федерации по вопросу совершенствования порядка судопроизводства при заключении досудебного соглашения о сотрудничестве» от 3 июля 2016 г. № 322-Ф3 // Российская газета. - 2016. 4 июля (№ 121).

15. Федеральный закон «О внесении изменений в Уголовный кодекс Российской Федерации и Уголовно-процессуальный кодекс Российской Федерации» от 29 июня 2009 г. № 141-Ф3 // Российская газета. $-2009 .-3$ июля (№ 121).

\section{REFERENCES}

1. Belkin A.R. Dosudebnoe soglashenie o sotrudnichestve nuzhdaetsya $v$ korrektivakh [Pre-trial agreement on cooperation requires adjustments]. Dosudebnoe soglashenie o sotrudnichestve (pravovye i kriminalisticheskie problemy) [Pre-trial cooperation 
agreement (legal and forensic issues)]. Voronezh, Izd-vo Voronezh. gos. un-ta, 2010. - pp. 73-84.

2. Kostenko N.S. Dosudebnoe soglashenie o sotrudnichestve $v$ ugolovnom protsesse: pravovye $i$ organizatsionnye voprosy zaklyucheniya i realizatsii: dis. ... kand. yurid. nauk [Pre-trial agreement on cooperation in criminal proceedings: legal and organizational issues the conclusion and implementation. Cand. jurid. sci. diss.]. Volgograd, 2013.238 p.

3. Kubrikova M.E. Aktualnye voprosy instituta dosudebnogo soglasheniya o sotrudnichestve: avtoref. dis. ... kand. yurid. nauk [Topical issues of the institute pre-trial agreement on cooperation. Cand. jurid. sci. abs. diss.]. Chelyabinsk, 2013. 25 p.

4. Perekrestov V.N. Priznanie viny $v$ otechestvennom ugolovnom sudoproizvodstve Rossiyskoy Federatsii: avtoref. dis. ... kand. yurid. nauk [A confession of guilt in a domestic criminal trial of the Russian Federation. Cand. jurid. sci. abs. diss.]. Krasnodar, 2012. 29 p.

5. Perekrestov V.N. Sovershenstvovanie sistemy garantiy dobrovolnosti priznaniya viny kak napravlenie modernizatsii ugolovno-protsessualnogo zakonodatelstva [Improving the safeguards system of voluntary admission of guilt as the direction of modernization of criminal procedure legislation]. Vestnik Volgogradskogo gosudarstvennogo universiteta. Seriya 5, Yurisprudentsiya [Science Journal of Volgograd State University. Jurisprudence], 2013, no. 2 (19), pp. 160-164.

6. Perspektivy vvedeniya v Rossiyskoy Federatsii instituta «sdelki s pravosudiem» [Prospects for the introduction of the institute of the Russian Federation "plea bargaining"]. Materialy parlamentskogo kruglogo stola v Gosudarstvennoy Dume Federalnogo Sobraniya Rossiyskoy Federatsii 08.02.2007 [The materials of the parliamentary round table in the State Duma of the Federal Assembly of the Russian Federation 08.02.2007]. Moscow, Izdanie Gos. Dumy, 2007. 40 p.

7. Pogodin S.B. Nekotorye aktualnye problemy primeneniya osobogo poryadka sudebnogo razbiratelstva $v$ sostyazatelnom ugolovnom protsesse [Some of the current problems of the application of a special order of the trial in the adversarial criminal process]. Rossiyskaya yustitsiya, 2009, no. 9, pp. 61-65.

8. Postanovlenie Plenuma VS RF «O praktike primeneniya sudami osobogo poryadka sudebnogo razbiratelstva ugolovnykh del pri zaklyuchenii dosudebnogo soglasheniya o sotrudnichestve» ot 28 iyunya 2012 g. № 16 [Resolution of the Plenum of the Russian Federation "On the practice of application by the courts of special order of the trial of criminal cases at the conclusion of the pre-trial agreement on cooperation" of June 28, 2012 no. 16]. Byulleten
Verkhovnogo Suda Rossiyskoy Federatsii, 2012, no. 9, pp. 19-22.

9. Sarkisyan T.B. Soglasitelnye protsedury $v$ ugolovnom sudoproizvodstve $i$ ikh primenenie $v$ stadii predvaritelnogo rassledovaniya: dis. ... kand. yurid. nauk [Conciliation proceedings in criminal trials and their application in the preliminary investigation stage. Cand. jurid. sci. diss.]. Krasnodar, 2012. 201 p.

10. Smirnov A.V. Osobyy poryadok prinyatiya sudebnogo resheniya pri zaklyuchenii dosudebnogo soglasheniya o sotrudnichestve [The special order of the court decision at the conclusion of the pre-trial agreement on cooperation]. Ugolovnyy protsess, 2009, no. 10 , pp. 5-14.

11. Spravka o rezultatakh obobshcheniya praktiki primeneniya sudami Saratovskoy oblasti v 2010 godu i pervom polugodii 2011 goda norm ob osobom poryadke prinyatiya sudebnogo resheniya pri zaklyuchenii dosudebnogo soglasheniya o sotrudnichestve ot 21.11.2011 [Information about the results of generalization of practice of application by courts of the Saratov region in 2010 and the first half of 2011 on the special rules of procedure for the adoption of the judgment at the conclusion of the pre-trial agreement on cooperation of 21.11.2011]. Saratovskiy oblastnoy sud: ofits. sayt. [Saratov regional court: official site]. Available at: http://oblsud.sar.sudrf.ru.

12. Ugolovnoe delo № 13/122-2014 v otnoshenii V., obvinyaemoy $v$ sovershenii prestupleniy, predusmotrennykh ch. 3 st. 30 , p. "a" ch. 4 st. 228.1 , ch. 1 st. 30 , p. "a, g" ch. 4 st. 228.1 , ch. 1 st. 30 , p. "a" ch. 4 st. 228.1 , ch. 1 st. 30 , p. "a" ch. 4 st. 228.1 , ch. 4 st. 150 UK RF [The criminal case no. 13/122-2014 with regard to B., accused of committing crimes under part 3 art. 30, point "a", part 4, art. 228.1, part 1 art. 30, points “a, g”, part 4 art. 228.1, part 1 art. 30, point "a" part 4 art. 228.1, part 1 art. 30, point “a"part 4 art. 228.1, part 4, art. 150 of the Criminal Code of the Russian Federation]. Deystvuyushchiy arkhiv Abdulinskogo rayonnogo suda Orenburgskoy oblasti za 2015 god [The current archive of the Abdulinsky District Court of the Orenburg region for 2015].

13. Ugolovnoe delo № 60/141-2014 v otnoshenii G. [The criminal case no. 60 / 141-2014 with respect to G.]. Deystvuyushchiy arkhiv Dzerzhinskogo rayonnogo suda g. Orenburga [The current archive of the Dzerzhinsky District Court of Orenburg].

14. Federalnyy zakon "O vnesenii izmeneniy v Ugolovno-protsessualnyy kodeks Rossiyskoy Federatsii po voprosu sovershenstvovaniya poryadka sudoproizvodstva pri zaklyuchenii dosudebnogo soglasheniya o sotrudnichestve" ot 3 iyulya 2016 g. № 322-FZ [Federal Law "On Amendments to the Criminal Procedure Code of the Russian Federation on measures to improve the order of proceedings at the conclusion of the pre-trial cooperation agreement" 
of July 3, 2016 no. 322-FL]. Rossiyskaya gazeta, 2016, July 4 (no. 121)

15. Federalnyy zakon "O vnesenii izmeneniy v Ugolovnyy kodeks Rossiyskoy Federatsii i Ugolovnoprotsessualnyy kodeks Rossiyskoy Federatsii" ot
29 iyunya 2009 g. № 141-FZ [Federal Law “On Amendments to the Criminal Code of the Russian Federation and the Criminal Procedure Code of the Russian Federation" of June 29, 2009 no. 141-FL]. Rossiyskaya gazeta, 2009, July 3 (no. 121).

\section{Information About the Author}

Olga N. Tisen, Candidate of Juridical Sciences, Senior Prosecutor, Department of Supervision over Federal Security, International Relations, Extremizm Prevention, Prosecutors Office of the Orenburg Region, Kobozeva St., 51, 460000 Orenburg, Russian Federation, Olga-tisen@yandex.ru.

\section{Информация об авторе}

Ольга Николаевна Тисен, кандидат юридических наук, старший прокурор отдела по надзору за федеральной безопасностью, межнациональным отношениям, противодействию экстремизму и терроризму, прокуратура Оренбургской области, ул. Кобозева, 51, 460000 г. Оренбург, Российская Федерация, Olga-tisen@yandex.ru. 